\title{
Correction of Tropical Rainfall Measuring Missions Satellite Data of Solar Radiation for the High Andean Areas of Peru
}

\author{
Odilon Correa $\mathrm{Cuba}^{1}$, Rosa Gabriela Coral Surco ${ }^{1} \&$ Juan José Zúñiga Negron² \\ ${ }^{1}$ Academic Directorate of Basic Sciences, National University José María Arguedas, Apurímac, Perú \\ ${ }^{2}$ Center for Research on Climate Change and Environmental Management, National University San Antonio Abad \\ del Cusco, Cusco, Perú \\ Correspondence: Odilon Correa Cuba, Academic Directorate of Basic Sciences, National University José María \\ Arguedas, Apurímac, Perú, Jr. Juan Francisco Ramos № 380, Andahuaylas, Perú. Tel: 195-4323-268. E-mail: \\ odiloncorrea@unajma.edu.pe
}

Received: December 31, 2020 Accepted: January 21, 2021 Online Published: May 10, 2021

\begin{abstract}
The spatial and temporal quantification of climatic elements is necessary in different regions of the world, as mitigation policies against climate change in recent years the use of renewable energies has been promoted, with solar radiation being an important element, the objective is to correct Tropical Rainfall Measuring Missions (TRMM) satellite data series of solar radiation with respect to the data observed through an automatic meteorological station for a short period at a point located in the southern Peruvian Andes, we proceeded to process the observed data and download satellite information, making use of From a mathematical model, the correction coefficients of the satellite data were determined; The multiplicative factor model better corrects the satellite information, the Pearson correlation improved from $\mathrm{R}=0.65$ to $\mathrm{R}=0.84$ for monthly solar radiation, in the series of satellite data corrected for 37 years, a trend was determined $-0.0006 \mathrm{Watt} / \mathrm{m} 2 / \mathrm{month}$.
\end{abstract}

Keywords: Apurímac, Peruvian Andes, solar radiation, TRMM

\section{Introduction}

Global warming and society's demand for electrical energy has intensified in recent decades, generating electrical energy from the sun is one of the challenges in recent decades (Grossi \& Coquet, 2017) (Mazorra Aguiar, Polo, Vindel, \& Oliver, 2019) the development of applications and research related to renewable energy (Jimenez, Will, \& Rodríguez, 2017) are prioritized lines in recent decades, also being necessary the characterization of solar energy resources for renewable energy technologies requires good precision (Jesus Polo et al., 2020), it has an impact on the economy (Stoffel et al., 2000), without data on solar resources we do not advance in research (Yang \& Bright, 2020) photovoltaic plants in areas where there are few records of solar radiation, after quality control (J. Polo et al., 2016), the availability of a high quality time and space series of solar radiation in situ is limited, it is about building through satellite images (Ameen et al., 2018) for the purpose of quantifying in regions where there is no climate information, the validation of solar radiation satellite data with respect to observed data is essential for later use in areas with a scarcity of observed data and they are quite similar (Ameen et al., 2018), knowing the exact data of the terrestrial solar radiation is enough to implement photovoltaic systems for the supply of electrical energy as well as for the detection of climate change (Stoffel et al., 2000), multispectral atmospheric correction being necessary to improve satellite data such as MODIS (Cao, Han, Zhang, \& Li, 2020), countries such as North Korea and South Korea to alleviate electricity crisis make energy explorations (Yeom et al., 2020), another technique used is in neural networks and mathematical models using climatic variables as input (Jimenez et al., 2017) (Lavorato, Lakkis, \& Canziani, 2013), too (Lavado \& Condom, 2010) proposes correcting satellite data on precipitation through the use of additive and multiplicative factors, throughout the Peruvian territory there is not enough climate information specifically the climate element solar radiation, local and regional policies are focused on the use of renewable energy, for this it has become essential to know the intensity of radiation and solar energy in time and space, in the high Andean areas of Peru the dehydration of the potato called chuño has been practiced for many generations, the entire process is based on radiation solar, for Andean cultures solar radiation is deity, in recent years chuño is of social and economic interest due to the guarantee of food safety, the objective of this study is to validate TRMM satellite data through data observed from a meteorological station automatic in situ for solar radiation in the period from 2014 to 2017 located in the p central art of the Chumbao river micro-basin in the 
Apurímac region.

\section{Method}

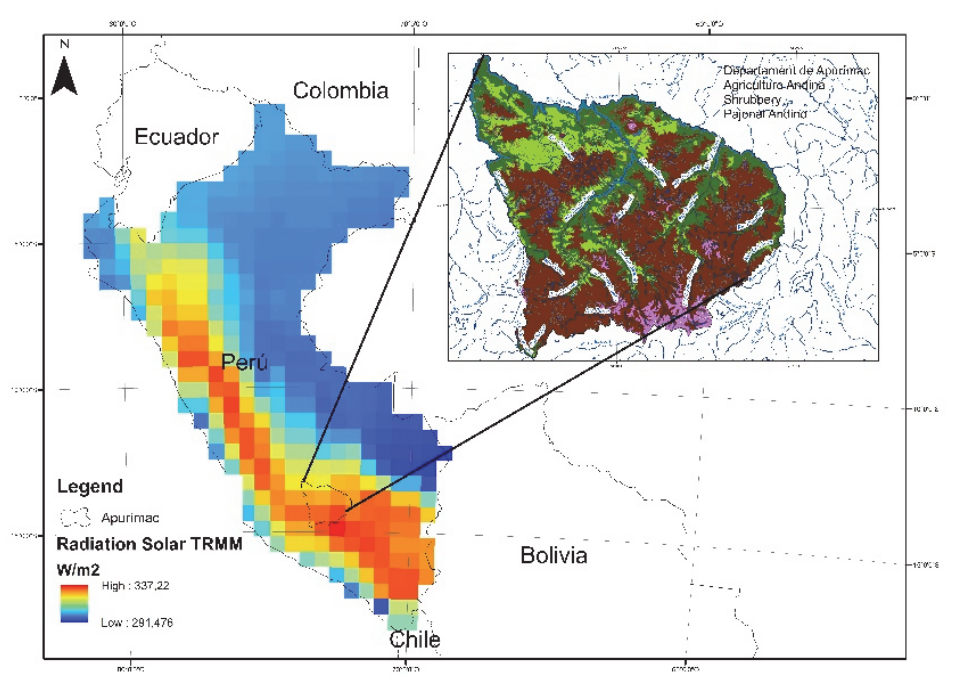

Figure 1. Geographical location of the study, on a map of Peru the TRMM solar radiation, important aspects about the Apurímac region

The research was carried out in a point of the high Andean zone of southern Peru, the Apurímac region, the region is characterized by the diversity of agricultural production, the main products being potatoes and corn, two types of data were considered, a long series of TRMM satellite information and, on the other hand, a series of observed data for a short period, the TRMM satellite monthly time series were downloaded from the page https://giovanni.gsfc.nasa.gov/giovanni// in its MERRA - 2 version, Model v5.12.4 with a resolution of $57 \mathrm{~km}$ for the period from 1980 to 2017, shows figure 1, while the observed data was recorded through the meteorological

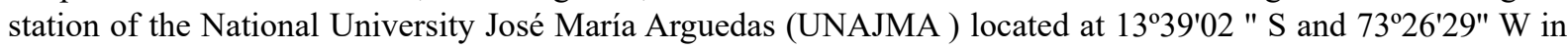
the central part of the Chumbao river micro-basin in the Apurímac region, DAVIS 6162C automatic station, the observed data were recorded with a frequency of $10 \mathrm{~min}$ for the years 2014 to 2017.

The technique to correct the TRMM satellite data series of solar radiation with respect to the observed data, uses a mathematical model called the multiplicative factor (Condom, Rau, \& Espinoza, 2011) who used this model to correct data series of monthly precipitation in the Peruvian Andes for a long period, another model that also corrects data is called additive factor, they have their mathematical procedure that is illustrated below.

Correction factor for multiplicative model, represented by $\Delta_{*} R S_{i}$ :

$\Delta_{*} R S_{i}=\frac{\mu_{\log \left(T R M M_{i}+1\right)}}{\mu_{\log \left(U N A J M A_{i}+1\right)}}$

Correction factor by additive model, represented by $\Delta_{+} R S_{i}$ :

$\Delta_{+} R S_{i}=\mu_{\log \left(\text { TRMM }_{i}+1\right)}-\mu_{\log \left(\text { UNAJMA }_{i}+1\right)}$

Where $\mathrm{i}=$ number of months $(1,2, \ldots, 12)$

$\mu_{\log \left(T R M M_{i}+1\right)}$ mean of TRMM satellite records transformed for month i.

$\mu_{\log \left(U N A J M A_{i}+1\right)}$ mean of records observed through the UNAJMA meteorological station transformed for the month i.

In these two equations, $\log \left(T R M M_{i}+1\right)$ and $\log \left(U N A J M A_{i}+1\right)$ is the base $10 \operatorname{logarithm}$ function of the 
monthly observed and satellite data, with the addition of one, respectively, the logarithm mathematical function in charge of the transformation.

Then applying the correction factor by the multiplicative and additive model respectively, corrected data is given by the following equation:

$$
\begin{aligned}
& T R M M_{i j}=\sqrt[\Delta_{*} R S_{i}]{\operatorname{TRMM}_{j}+1}-1 \\
& T R M M_{i j}=\sqrt[\Delta_{+} R S_{i}]{T R M_{j}+1}-1
\end{aligned}
$$

For month $i$ of year $j$, that is $i=$ number of months $(1,2, \ldots, 12)$ and $j=$ year of series $(2014, \ldots, 2017)$.

\section{Results and Discussion}

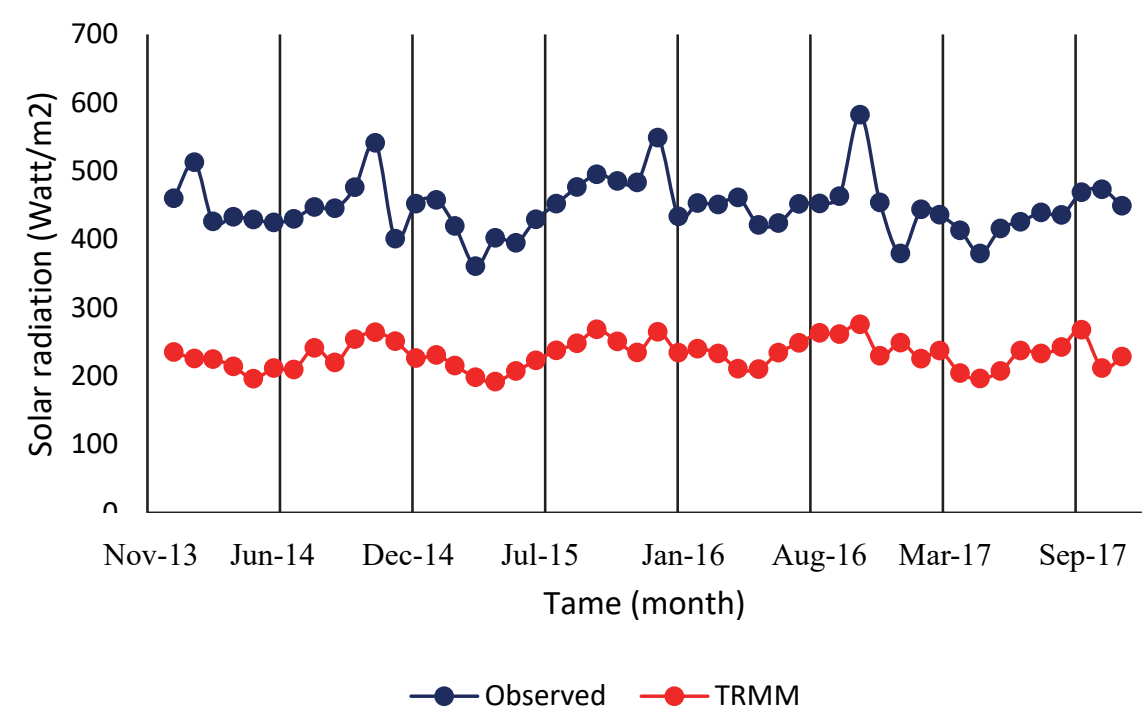

Figure 2. Observed satellite solar radiation and TRMM without correction

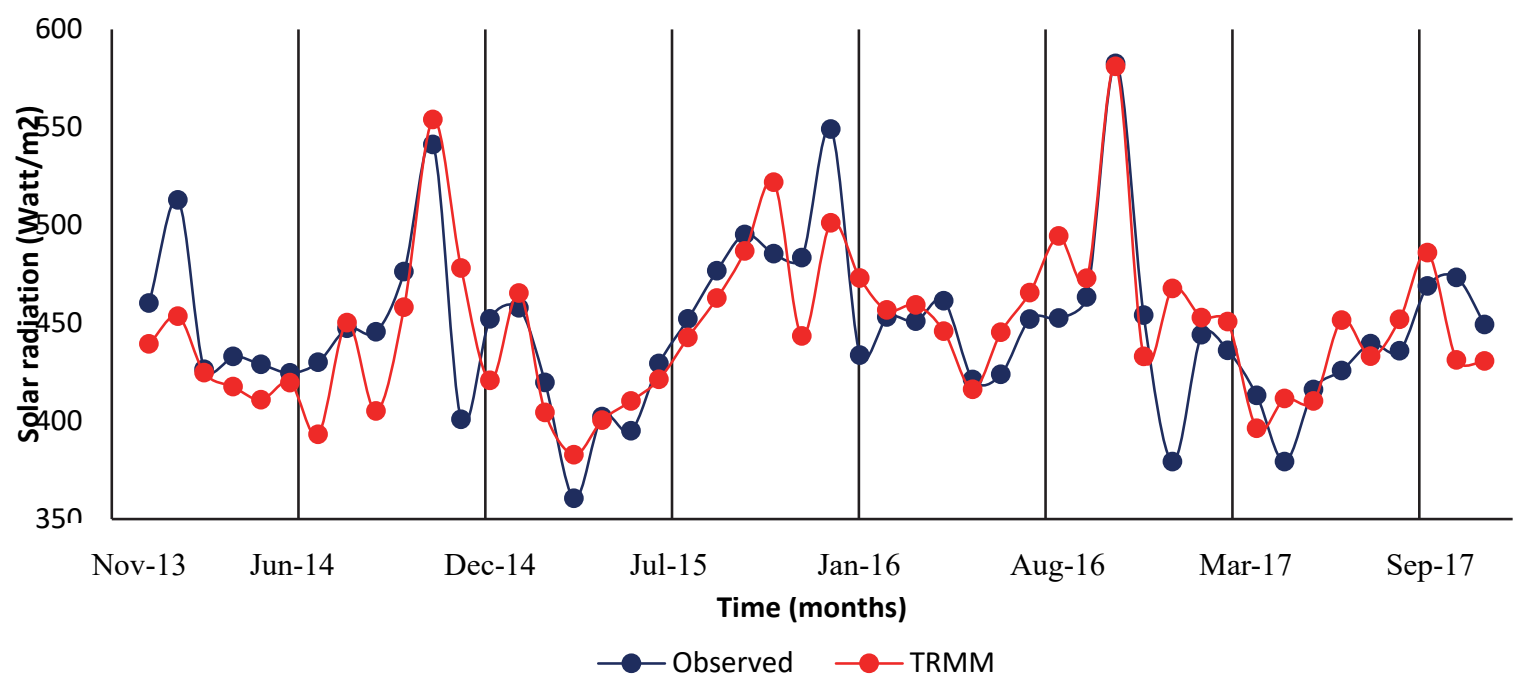

Figure 3. TRMM satellite solar radiation corrected with multiplicative factor 

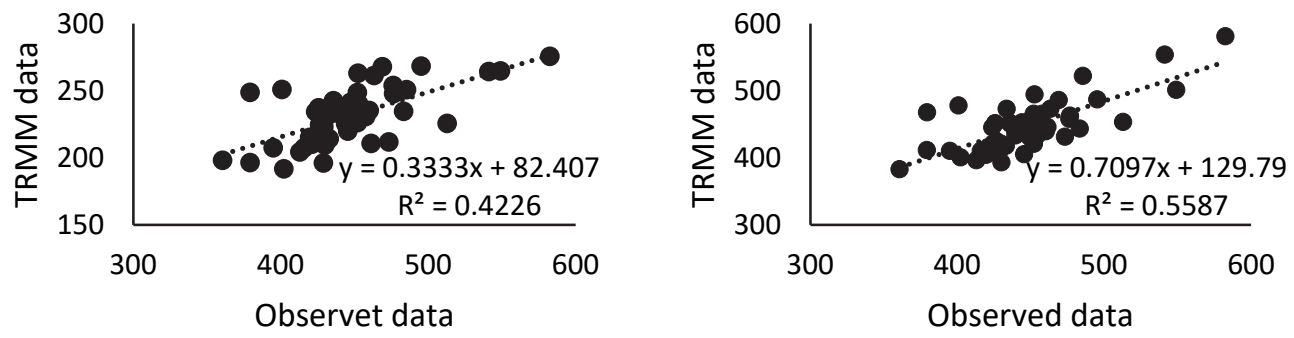

Figure 4. Dispersion diagram of observed solar radiation and TRMM for the period from 2014 to 2017, the first before correcting and the second after correction

In table 1 we show, the procedures that have been followed to find the value of the coefficient for the month of January, making use of equation 1, the last column of the same table shows the corrected satellite data. Equation 3 , the same procedure was carried out for the other months, finally it is shown that this model corrects the satellite data with respect to the observed data.

Table 1. Example of calculating the coefficient for the month of January, the last column presents satellite data corrected by the multiplicative factor

\begin{tabular}{cccccc}
\hline Year & $\begin{array}{c}\text { UNAJMA } \\
\text { solar radiation }\end{array}$ & $\begin{array}{c}\text { TRMM solar } \\
\text { radiation }\end{array}$ & $\log ($ UNAJMA+1) & $\log (\mathrm{TRMM}+1)$ & $T_{R M M_{i j}}$ \\
\hline 2014 & 460.17 & 235.12 & 2.66 & 2.37 & 439.32 \\
2015 & 452.14 & 226.19 & 2.66 & 2.36 & 420.81 \\
2016 & 549.02 & 264.69 & 2.74 & 2.42 & 501.19 \\
2017 & 379.34 & 248.73 & 2.58 & 2.40 & 467.69 \\
\hline \multicolumn{7}{r}{} \\
& Average & 2.66 & 2.39 & \\
& $\Delta_{*} R S_{i}=0.90$ & & \\
\hline
\end{tabular}

After controlling the median and standard deviation of the observed data series and TRMM, the monthly correction factor coefficients for the TRMM satellite data were determined with respect to the observed data, using the equations 3 mentioned in the methodology, multiplicative model, the correlation between observed data and TRMM prior to correction was too low, with a Pearson correlation coefficient $r=0.65$ and slope of the line 0.33 , shown in figure 2, knowing this correlation in order to improve the degree of approximation of data, the multiplicative model equation 3 was used, being the best data corrector this multiplicative model where the monthly correction coefficients were quantified, it is shown in table 2.

Table 2. Coefficients of the monthly correction factor through the multiplicative models

\begin{tabular}{lllllllllllll}
\hline Months & Jan & Feb & Mar & Apr & May & Jun & Jul & Aug & Sep & Oct & Nov & Dec \\
\hline Coeff. & 0,90 & 0,89 & 0,90 & 0,89 & 0,88 & 0,89 & 0,89 & 0,90 & 0,90 & 0,90 & 0,88 & 0,90 \\
\hline
\end{tabular}

Once the monthly coefficients have been determined, the Pearson correlation coefficient shows significant improvements, being $r=0.84$ as the slope of the line reaches 0.71 figure 3 , this without considering clear skies or hours with the presence of clouds that you can overestimate or underestimate (Mazorra Aguiar et al., 2019) satellite solar radiation, the scatter diagram before and after correction shows figure 4 between observed data and TRMM for a period of 4 years; The methodology used guarantees the suitability of TRMM for high Andean areas as well as other techniques for different satellites (Mazorra Aguiar et al., 2019), Taking into account that TRMM has been from 1980 to the present, the correction coefficients found for a short period of 4 years is applicable for long 
periods and places where data records are scarce (Jesus Polo et al., 2020) it is sometimes called site adaptation using different techniques.

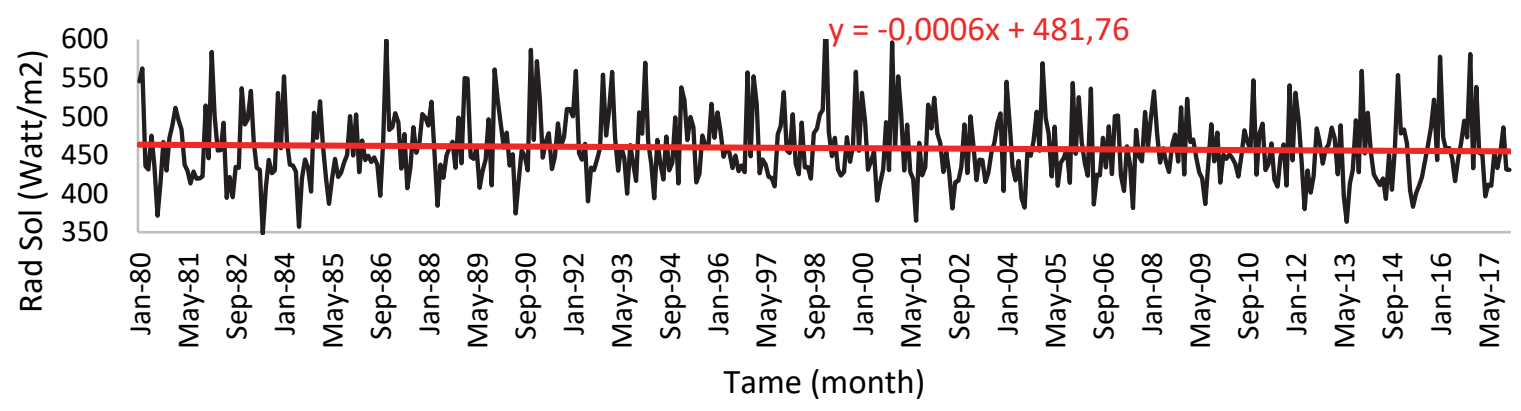

Figure 5. Corrected solar radiation temporal data series for the Chumbao river micro-basin

The monthly determined coefficients were applied to the TRMM data series for the period from 1980 to 2017 , finally they were corrected for the long period figure 5 which allows knowing series of solar radiation with a good approximation for areas in the high Andean areas of the In southern Peru, precipitation in the high Andean areas is decadal and interdecadal (Segura, Espinoza, Junquas, \& Takahashi, 2016) the variation in solar radiation apparently is also decadal as shown in figure 5, said decadal variation was clearly observed until 2002 with the presence of some anomalies, from 2003 it seems that solar radiation has decreased considerably and it can also be observe in the diagram a disorder where decadal variation cannot be identified, which could be attributed to the effects of climate change (Stoffel et al., 2000), for the monthly data considered for 38 years, the trend is -0.0006 Watt / $\mathrm{m} 2$ / month, this negative trend may not be significant but it is surprising in the way that it varies, it deserves a better analysis to see the decadal or interdecadal behaviour of the Solar radiation, as well as anomalies that occur over time, corrected TRMM satellite solar radiation data guarantees spatial and temporal use for research at least in photovoltaic areas and as an aid for making the right policies at the local, regional level and national.

\section{Conclusions}

Under the scenarios of unusual presence of regional climatic variabilities, population growth and the demand for electrical energy for industrial purposes, photovoltaic energy generation becomes a challenge, in this study the monthly coefficients have been found as correction factors through the multiplicative models, to correct the TRMM satellite data series with respect to the data observed for a point in the Andes of southern Peru, this result can be generalized for the entire mountain range of the Peruvian territory, with this it will be possible to accurately determine the monthly value of solar radiation for places where there are no records of observed solar radiation, which it is suggested to test for the coast and the Peruvian Amazon.

\section{References}

Ameen, B., Balzter, H., Jarvis, C., Wey, E., Thomas, C., \& Marchand, M. (2018). Validation of hourly global horizontal irradiance for two satellite-derived datasets in northeast Iraq. Remote Sensing, 10(10), https://doi.org/10.3390/rs10101651

Cao, H., Han, L., Zhang, T., \& Li, L. (2020). An Atmospheric Correction Algorithm for GF-2 Image Based on Radiative Transfer Model. IOP Conference Series: Materials Science and Engineering, 780(3), https://doi.org/10.1088/1757-899X/780/3/032040

Condom, T., Rau, P., \& Espinoza, J. C. (2011). Correction of TRMM 3B43 monthly precipitation data over the mountainous areas of Peru during the period 1998-2007. Hydrological Processes, 25(12), 1924-1933. https://doi.org/10.1002/hyp.7949

Grossi, H., \& Coquet, E. (2017). La pérdida de datos diarios de irradiación solar global y una evaluación sobre su influencia en los promedios mensuales. Revista de Climatología, 17, 45-57. Retrieved from http://www.climatol.eu/reclim/reclim17e.pdf

Jimenez, V. A., Will, A., \& Rodríguez, S. (2017). Estimación de Radiación Solar Horaria Utilizando Modelos Empíricos y Redes Neuronales Artificiales. Ciencia y Tecnología, 1(17), 29. 
https://doi.org/10.18682/cyt.v1i17.608

Lavado, P. R. A. U., \& Condom, T. (2010). Análisis espacio temporal de la precipitación en las zonas de montaña de Spatio-temporal analysis of rainfall in the mountain regions of Peru (1998-2007), 29(2), 16-29.

Lavorato, M. B., Lakkis, S. G., \& Canziani, P. O. (2013). Radiación solar : métodos de regresión para datos del 2010-2013 en Buenos Aires Solar radiation: regression methods for data period 2010-2013 in Buenos Aires, 26.

Mazorra Aguiar, L., Polo, J., Vindel, J. M., \& Oliver, A. (2019). Analysis of satellite derived solar irradiance in islands with site adaptation techniques for improving the uncertainty. Renewable Energy, 135, 98-107. https://doi.org/10.1016/j.renene.2018.11.099

Polo, J., Wilbert, S., Ruiz-Arias, J. A., Meyer, R., Gueymard, C., Súri, M., ... Cebecauer, T. (2016). Preliminary survey on site-adaptation techniques for satellite-derived and reanalysis solar radiation datasets. Solar Energy, 132, 25-37. https://doi.org/10.1016/j.solener.2016.03.001

Polo, Jesus, Fernández-Peruchena, C., Salamalikis, V., Mazorra-Aguiar, L., Turpin, M., Martín-Pomares, L., ... Remund, J. (2020). Benchmarking on improvement and site-adaptation techniques for modeled solar radiation datasets. Solar Energy, 201(October 2019), 469-479. https://doi.org/10.1016/j.solener.2020.03.040

Segura, H., Espinoza, J. C., Junquas, C., \& Takahashi, K. (2016). Evidencing decadal and interdecadal hydroclimatic variability over the Central Andes. Environmental Research Letters, 11(9). https://doi.org/10.1088/1748-9326/11/9/094016

Stoffel, T. L., Reda, I., Myers, D. R., Renne, D., Wilcox, S., \& Treadwell, J. (2000). Current issues in terrestrial solar radiation instrumentation for energy, climate, and space applications. Metrologia, 37(5), 399-402. https://doi.org/10.1088/0026-1394/37/5/11

Yang, D., \& Bright, J. M. (2020). Worldwide validation of 8 satellite-derived and reanalysis solar radiation products: A preliminary evaluation and overall metrics for hourly data over 27 years. Solar Energy, (April), 1-18. https://doi.org/10.1016/j.solener.2020.04.016

Yeom, J. M., Deo, R. C., Adamwoski, J. F., Chae, T., Kim, D. S., Han, K. S., \& Kim, D. Y. (2020). Exploring solar and wind energy resources in North Korea with COMS MI geostationary satellite data coupled with numerical weather prediction reanalysis variables. Renewable and Sustainable Energy Reviews, 119(xxxx), 109570. https://doi.org/10.1016/j.rser.2019.109570

\section{Copyrights}

Copyright for this article is retained by the author(s), with first publication rights granted to the journal.

This is an open-access article distributed under the terms and conditions of the Creative Commons Attribution license (http://creativecommons.org/licenses/by/4.0/). 